\title{
INTERACTION OF D, L-erythro- AND D,L-threo- $\gamma$-FLUOROMETHOTREXATE WITH HUMAN LEUKEMIA CELL DIHYDROFOLATE REDUCTASE
}

\author{
JohN J. MCGuire, ${ }^{*} \dagger$ William H. Haile* and James K. Coward $\ddagger$ \\ *Grace Cancer Drug Center, Roswell Park Memorial Institute, Buffalo, NY 14263; and \\ $\ddagger$ Departments of Chemistry and Medicinal Chemistry, University of Michigan, Ann Arbor, \\ MI 48109, U.S.A.
}

(Received 6 January 1989; accepted 24 May 1989)

\begin{abstract}
Gamma-fluoromethotrexate (FMTX) is a poorly glutamylated mimic of the anti-cancer drug methotrexate (MTX) which is useful in studies of the roles of MTX poly- $\gamma$-glutamates. A second chiral center occurs at C-4 of the 4-fluoroglutamate used to synthesize FMTX and, as a consequence, FMTX occurs as both $\mathrm{D}, \mathrm{L}$-erythro and $\mathrm{D}, \mathrm{L}-$ threo diastereomers. The interaction of both diastereomers with intracellular dihydrofolate reductase has been examined in the human leukemia cell line CCRF-CEM, using a centrifugal column technique. Measurements of the rate at which radiolabel was displaced from $\left[{ }^{3} \mathrm{H}\right]$ MTX-saturated dihydrofolate reductase following suspension of the cells in unlabeled drug indicated that MTX and the erythro isomer of FMTX gave essentially the same rate of displacement; the rate of displacement by the threo isomer of FMTX was slower, but the interpretation of these data was ambiguous since the rate of transport of threo-FMTX may have been limiting. In reciprocal experiments in which dihydrofolate reductase was saturated with $\left[{ }^{3} \mathrm{H}\right]$ erythro-FMTX, the erythro isomer and MTX again behaved equivalently in terms of displacement. When dihydrofolate reductase was saturated with $\left[{ }^{3} \mathrm{H}\right]$ threo-FMTX, the radiolabel was clearly displaced at a much faster rate than either other radiolabel regardless of whether the displacing agent was MTX or the isomer. These results indicate a distinct stereospecificity for interaction of inhibitor with dihydrofolate reductase in which the threo isomer has a faster off-rate. Of the two FMTX diastereomers, the erythro isomer thus most closely mimics the properties of MTX.
\end{abstract}

The role(s) of the poly $(\gamma$-glutamyl)metabolites of MTX $\$$ in the cytotoxic mechanism and in the therapeutic efficacy of this agent are currently topics of wide interest. The results from a number of lab. oratories using different model systems (reviewed in Refs 1 and 2) are consistent with these metabolites being involved in retaining intracellular concentrations of MTX in excess of those in the extracellular space and above the level of DHFR, as is required for cytotoxicity [3]. MTX polyglutamates may also directly inhibit sites in folate metabolism other than DHFR, such as thymidylate synthase [4] or aminoimidazolecarboxamide ribotide transformylase [5], thereby increasing the blockade of the pyrimidine and purine biosynthetic pathways caused by the MTX-induced decrease in reduced folate co-factors. These conclusions have been supported, in general, by investigations in which the rate and/or amount of synthesis of MTX polyglutamates has been correlated with the property of interest.

$\dagger$ Correspondence: John J. McGuire, Ph.D., Grace Cancer Drug Center, Roswell Park Memorial Institute, 666 Elm St., Buffalo, NY 14263, U.S.A.

\& Abbreviations: MTX, methotrexate (4-amino-10methylpteroyl-glutamic acid); FMTX, $\gamma$-fluoromethotrexate [4-amino-10-methylpteroyl(D, L-erythro, threo-4fluoroglutamic acid)]; eFMTX, D,L-erythro- $\gamma$ fluoromethotrexate [4-amino-10-methylpteroyl-(4fluoro[2S,4R;2R,4S] glutamic acid)]; tFMTX, D, L-threo$\gamma$-fluoromethotrexate [4-amino-10-methylpteroyl-(4-fluoro [2S,4S;2R,4R] glutamic acid)]; DHFR, dihydrofolate reductase (EC 1.5.1.3); and HEPES, N-2hydroxyethylpiperazine- $N^{\prime}$-2-ethanesulfonic acid.
Another strategy for investigating the significance of MTX polyglutamates in cytotoxicity and therapeutic efficacy is the use of a nonglutamylatable mimic of MTX in comparative studies with MTX itself $[6-8]$. Such a mimic should have biochemical properties identical to those of MTX, except that it would be unable to form polyglutamate derivatives. The difference in the effects on cytotoxicity or efficacy between MTX and the mimic under appropriately controlled conditions would be directly attributable to the effects of the polyglutamates.

A mimic has been prepared by the substitution of 4-fluoroglutamate [9] for glutamate in MTX, thereby creating the analog FMTX [6]. Our initial studies were performed with FMTX that was a mixture of four isomers since the FMTX was chemically synthesized [6] from D,L-erythro,threo-4-fluoroglutamate. These studies indicated that FMTX was poorly glutamylated; however, its other biochemical properties were very similar to those of MTX [6]. Subsequent studies of the individual erythro and threo diastereomers [8] indicated that, although both inhibited isolated DHFR to the same extent as MTX (by $\mathrm{IC}_{50}$ ) and both were poor substrates for glutamylation, the erythro isomer was transported more nearly like MTX.

Since the usefulness of either erythro-FMTX or threo-FMTX in the comparative studies referred to above is critically dependent on the fidelity of their biochemical properties to those of MTX (except for glutamylation), we have continued our studies of these properties in detail. We have focused on DHFR since DHFR is the principal cellular target 
of MTX [10]. Both diastereomers of FMTX inhibit isolated DHFR with $\mathrm{IC}_{50}$ values equivalent to that of MTX [8]; $\mathrm{IC}_{50}$ values, however, offer only a rough estimate of "stoichiometric" interactions of inhibitors with this enzyme. As a more sensitive measurement of the interaction of the erythro and threo isomers of FMTX, we therefore chose to follow the approach used previously with MTX by Cohen $e t$ al. [11], in which dissociation of radiolabeled ligand from DHFR is measured in intact cells.

\section{MATERIALS AND METHODS}

Uptake, efflux, and displacement. Drug uptake was performed at CCRF-CEM [12] cell densities of $2 \times 10^{7}$ cells $/ \mathrm{ml}$ in RPMI 1640 (GIBCO) supplemented with $10 \%(\mathrm{v} / \mathrm{v})$ of horse serum (GIBCO) and $20 \mathrm{mM}$ HEPES-NaOH, $\mathrm{pH} 7.5$, held at $37^{\circ}$ as previously described [8]. Cells were preloaded with $\left[{ }^{3} \mathrm{H}\right] \mathrm{MTX}(5 \mathrm{~min} ; 2 \mu \mathrm{M} ; 1.5 \mu \mathrm{Ci} / \mathrm{ml}$; $700 \mathrm{cpm} / \mathrm{pmol}),\left[{ }^{3} \mathrm{H}\right] \mathrm{eFMTX}(15 \mathrm{~min} ; 4 \mu \mathrm{M} ; 0.5 \mu \mathrm{Ci} /$ $\mathrm{ml} ; 90 \mathrm{cpm} / \mathrm{pmol})$, or $\left[{ }^{3} \mathrm{H}\right] \mathrm{tFMTX}(20 \mathrm{~min} ; 4 \mu \mathrm{M}$; $0.5 \mu \mathrm{Ci} / \mathrm{ml} ; 80 \mathrm{cpm} / \mathrm{pmol}$ ) to achieve saturation of DHFR with minimal unbound drug; the time required was determined in preliminary studies, and DHFR saturation was verified in each experiment. At the end of the pre-loading period, the cells were diluted 2.5-fold in iced complete medium, chilled, and centrifuged at $4^{\circ}(5 \mathrm{~min} ; 1000 \mathrm{~g})$. The supernatant fraction was removed and the cell pellet was triturated in $40 \mathrm{ml}$ of iced complete medium and recentrifuged. The resulting cell pellet was rapidly dispersed in a volume of complete medium $\left(37^{\circ}\right)$ which approximately restored the original cell density; the actual cell density was determined. Aliquots of the cell suspension were removed at 0,15 and $30 \mathrm{~min}$. After the 30-min effux period, the cell suspension was divided and the appropriate concentration of displacement agent was added. At 5 , $10,20,30$, and $45 \mathrm{~min}$, duplicate $1-\mathrm{ml}$ samples of cell suspension were removed from each treatment, washed free of extracellular drug with repeated iced saline washes [8], and stored frozen $\left(-90^{\circ}\right)$ until processed for total and DHFR-bound drug (below). Dilution in iced medium and chilling during the wash were essential to stopping further uptake and to preventing the metabolism of intracellular $\left[{ }^{3} \mathrm{H}\right] \mathrm{MTX}$ to polyglutamates. If this washing was performed at room temperature, up to $34 \%$ of the drug could be converted to metabolites (data not shown).

Total and DHFR-bound intracellular drug. Cell pellets from transport studies were stored until processing ( $\leqslant 3$ days). When processed, tubes containing the cell pellets were placed in ice water and $1 \mathrm{ml}$ of iced lysis buffer (modeled after Fry et al. [13]) was added. Lysis buffer contained $50 \mathrm{mM}$ citric acidsodium citrate, $\mathrm{pH} 6.0,50 \mathrm{mM} 2$-mercaptoethanol, $50 \mu \mathrm{M}$ NADPH, and $2 \mathrm{mg} / \mathrm{ml}$ bovine serum albumin (fraction V; Sigma Chemical Co., St Louis, MO) and was made immediately before use to minimize nonenzymatic hydrolysis of NADPH. Following disruption of the cell pellet with a pasteur pipette, cells were quàntitatively lysed by 1 cycle of freezing and thawing using a dry-ice/methanol bath. The supernatant fraction was obtained by centrifuging at $1860 \mathrm{~g}$ for $10 \mathrm{~min}$. Total intracellular label was obtained by mixing $350 \mu \mathrm{l}$ of the supernatant fraction with $150 \mu \mathrm{l}$ of $50 \mathrm{mM}$ citric acid-sodium citrate, $\mathrm{pH} 6.0$, and $5.5 \mathrm{ml}$ of liquid scintillation counting fluid and quantitating in a liquid scintillation counter (Beckman model LS 1801). DHFR-bound radiolabel was measured using a centrifugal column procedure $[8,13]$ to separate free and bound drug. Centrifugal columns were $5-\mathrm{ml}$ disposable plastic syringes (Becton-Dickson) plugged with a porous polyethylene disc $(70 \mu \mathrm{m}$ pore size; Bel-Art, Pequannock, NJ) covered with a Whatman $\mathrm{GF} / \mathrm{C}$ filter disc, both cut with a number 8 cork borer. Syringes were filled to the $5 \mathrm{ml}$ line with Sephadex G-25 (medium; Pharmacia, Piscataway, NJ) equilibrated with $50 \mathrm{mM}$ citric acid-sodium citrate, $\mathrm{pH} 6.0$. The resultant columns were centrifuged dry $(1000 \mathrm{~g} ; 5 \mathrm{~min})$. An aliquot $(500 \mu \mathrm{l})$ of the cell supernatant fraction (above) was layered evenly onto the gel bed, the column was re-centrifuged, and the pass-through containing DHFR-bound radiolabel was collected directly into a miniature scintillation vial and quantitated as above. Control experiments [8] indicated that this procedure quantitatively measured the total and DHFR-bound intracellular material. Half-time of displacement and $k_{\text {off }}$ values were calculated from linear regression analysis of plots of the logarithm of DHFR-bound radioactivity versus time [11].

Analysis of metabolism and degradation of radiolabel. Intracellular drug was analyzed for metabolites and degradation products as previously described [14].

Materials. MTX was the gift of the Lederle Division of American Cyanamid. MTX containing racemic, $D, L$-glutamate rather than the normal $L$ glutamate was obtained from the Aldrich Chemical Co. (Milwaukee, WI). The D,Lerythro and D,Lthreo diastereomers of FMTX and their tritiated counterparts were synthesized as previously described [8]. In this synthetic scheme, the $D-$ and $L_{-}$ enantiomers of each diastereomer would be pronounced in a $1: 1$ ratio. $\left[{ }^{3} \mathrm{H}\right] \mathrm{MTX}$ was purchased from Moravek Biochemicals, Inc. (Brea, CA).

\section{RESULTS}

Uptake of $\left[{ }^{3} \mathrm{H}\right] M T X$ to saturate DHFR. CCRFCEM cells exposed to $2 \mu \mathrm{M}\left[{ }^{3} \mathrm{H}\right] \mathrm{MTX}$ for $5 \mathrm{~min}$ (Fig. 1) accumulated intracellular drug concentrations of $9.1 \mathrm{pmol} / 10^{7}$ cells, exceeded the level of DHFR, and saturated the high affinity binding capacity of DHFR $\left(7.4 \mathrm{pmol} / 10^{7}\right.$ cells $)$. At longer periods of uptake $(10-30 \mathrm{~min})$, there was an increase in unbound drug but the level of DHFR-bound $\left[{ }^{3} \mathrm{H}\right]$ MTX remained constant (not shown). Using $10 \mathrm{~min}$ of uptake, this level of unbound drug allowed partial conversion of the intracellular drug to a polyglutamate form, 4. amino-10-methylpteroylglutamyl- $\gamma$-glutamate, and, at the end of efflux or at the end of the control displacement period, $14-15 \%$ of the intracellular radiolabeled drug was present as this metabolite. Using $5 \mathrm{~min}$ of influx, $\geqslant 94 \%$ of the intracellular label was recovered as MTX at the end of efflux or displacement, while less than $4 \%$ was recovered as the metabolite. Since at $5 \mathrm{~min}$, there were not significant levels of metabolites or degradation products of radiolabeled MTX, and DHFR was saturated, 


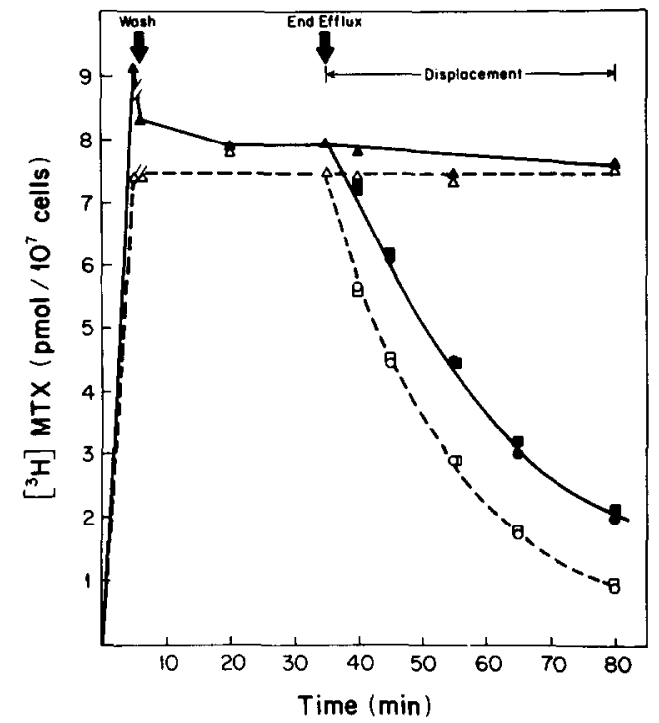

Fig. 1. Time course in CCRF-CEM cells for uptake, efflux, and displacement of $\left[{ }^{3} \mathrm{H}\right]$ MTX by MTX or FMTX isomers. During uptake, $2 \mu \mathrm{M}$ extracellular [ $\left.{ }^{3} \mathrm{H}\right] \mathrm{MTX}$ was present. Closed symbols are used for total intracellular drug under the particular condition, while open symbols are DHFRbound drug only. Triangles $(\Delta)$ stand for drug during uptake and efflux, and also for drug in the water displacement control. Circles $(O)$ stand for ${ }^{3} \mathrm{H}$-labeled drug in the presence of $10 \mu \mathrm{M}$ extracellular MTX. Squares ( $\square$ ) stand for ${ }^{3} \mathrm{H}$-labeled drug in the presence of $20 \mu \mathrm{M}$ extracellular $\mathrm{D}, \mathrm{L}-\mathrm{eFMTX}(10 \mu \mathrm{M}$ active isomer). All points are averages of duplicate determinations.

5 min was chosen as an appropriate influx time. When cells exposed for $5 \mathrm{~min}$ were washed and placed in drug-free medium (Fig. 1), the total intracellular drug declined after $30 \mathrm{~min}$ to a steady state $\left(7.9 \mathrm{pmol} / 10^{7}\right.$ cells) which approximated the level of DHFR-bound $\left[{ }^{3} \mathrm{H}\right] \mathrm{MTX}$.

Displacement of $\left[{ }^{3} \mathrm{H}\right] M T X$ from intracellular $D H F R$. If nonradioactive extracellular M'TX $(10 \mu \mathrm{M})$ was added to cell cultures containing $\left[{ }^{3} \mathrm{H}\right]$ MTX saturated DHFR, but no unbound drug, there was a first order loss of both total (Fig. 1) and DHFR-bound (Figs 1 and 2) $\left[{ }^{3} \mathrm{H}\right]$ MTX over a 45min displacement period. By 45 min over $87 \%$ of the [ $\left.{ }^{3} \mathrm{H}\right] \mathrm{MTX}$ had been displaced from DHFR. If nonradioactive eFMTX* $(10 \mu \mathrm{M})$ was added, there was again displacement of both total (Fig. 1) and DHFR-bound (Figs 1 and 2) $\left[{ }^{3} \mathrm{H}\right] \mathrm{MTX}$ which followed a time course nearly identical to that of MTX and reached a similar level after $45 \mathrm{~min}$. Control cells showed constant levels of both total and DHFRbound $\left[{ }^{3} \mathrm{H}\right] \mathrm{MTX}$ during the entire displacement period (Figs 1 and 2). Similar studies of displacement

* The eFMTX and tFMTX diastereomers are each mixtures of D- and L-enantiomers; the concentration presented, however, is that of the L-enantiomer only (i.e. one half of the total drug concentration assuming an equal distribution between $\mathrm{D}$ - and $\mathrm{L}$-forms). The D-enantiomer of each diastereomer was assumed to be biologically inactive since the MTX analog containing D-glutamate has no biological activity $([8,15]$; see text below).

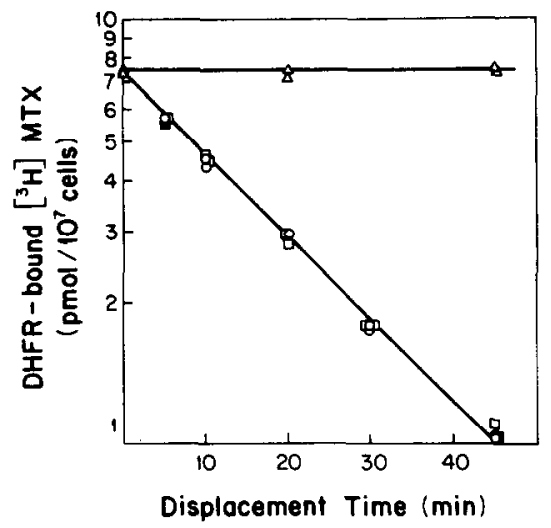

Fig. 2. Displacement of $\left[{ }^{3} \mathrm{H}\right] \mathrm{MTX}$ from intracellular DHFR by MTX or eFMTX. DHFR was saturated with $\left[{ }^{3} \mathrm{H}\right] \mathrm{MTX}$ and quantitated as described in the legend of Fig. 1 and in Materials and Methods. Displacement of this radiolabel by $10 \mu \mathrm{M}$ MTX (O), $20 \mu \mathrm{M}$ eFMTX $(10 \mu \mathrm{M}$ active isomer $)$ $(\square)$, or the volume equivalent of water $(\triangle)$ was determined as a function of time.

Table 1. Half-time of displacement of $\left[{ }^{3} \mathrm{H}\right] \mathrm{MTX}$ from intracellular CCRF-CEM DHFR by MTX or FMTX isomers

\begin{tabular}{cccc}
\hline $\begin{array}{c}\text { Extracellular } \\
\text { concentration } \\
(\mu \mathrm{M})\end{array}$ & \multicolumn{3}{c}{ Half-time value (min) } \\
\cline { 2 - 4 } & MTX & eFMTX & tFMTX \\
\hline 10 & $15.8 \pm 0.8^{*}$ & $16.1 \pm 0.9+$ & 21.4 \\
5 & 16.9 & 17.5 & ND \\
2 & 19.4 & 20.2 & ND \\
\hline
\end{tabular}

All determinations, except as noted, are averages of closely agreeing duplicates. Half-time values were determined by linear regression analysis of plots of the logarithm of DHFR-bound drug versus time ( $0-45 \mathrm{~min}$ of displacement). DHFR-bound drug was determined as described in Materials and Methods.

* Value is average \pm SD $(N=5)$.

$\dagger$ Value is average $\pm S D(N=3)$.

$\ddagger \mathrm{ND}=$ not determined.

of radiolabel from $\left[{ }^{3} \mathrm{H}\right] \mathrm{MTX}$-saturated DHFR were undertaken over a range of extracellular concentrations of MTX, eFMTX, or tFMTX. The results, quantitated as the half-time of displacement (Table 1), demonstrated that, at extracellular concentrations as low as $2 \mu \mathrm{M}$, eFMTX and MTX behaved very similarly. Displacement of $\left[{ }^{3} \mathrm{H}\right] \mathrm{MTX}$ by tFMTX had a significantly longer half-time at the highest concentration tested and, therefore, lower concentrations were not tested. Plots of log DHFRbound $\left[{ }^{3} \mathrm{H}\right]$ MTX versus time when tFMTX was the displacing agent displayed slight curvature, and this may reflect some difference in the binding of tFMTX to DHFR. Higher concentrations of the individual isomers were not tested, in order to conserve material, but increasing the extracellular concentration of MTX or the mixed diastereomer erythro,threo-FMTX [6] to $20 \mu \mathrm{M}$ did not affect the half-time of displacement.

The erythro and threo diastereomers of FMTX 
Table 2. Half-time of displacement of $\left[{ }^{3} \mathrm{H}\right] \mathrm{FMTX}$ isomers from intracellular CCRF-CEM DHFR by MTX or FMTX isomers

\begin{tabular}{llccc}
\hline & \multicolumn{2}{c}{$\begin{array}{c}\text { Extracellular concentration } \\
(\mu \mathrm{M})\end{array}$} & \multicolumn{3}{c}{ Half-time value (min) } \\
\cline { 3 - 5 } & & MTX & eFMTX & tFMTX \\
\hline (A) & DHFR saturated with [ ${ }^{3}$ H] erythro-FMTX & & & ND $^{*}$ \\
& 10 & $19.6 ; 20.0$ & $20.3 ; 21.3$ & ND $^{*}$ \\
& 5 & $19.3 ; 19.1$ & $21.2 ; 20.1$ & ND $^{*}$ \\
& 2 & $20.7 \pm 1.0$ & $22.3 \pm 2.8$ & ND $^{*}$ \\
& 0.5 & $27.4 ; 29.0$ & $33.5 ; 31.3$ & $12.9 ; 13.2$ \\
\hline
\end{tabular}

Determinations from two separate experiments are presented; at the $2 \mu \mathrm{m}$ value in experiment $\mathrm{A}$ the two values for MTX varied significantly so the experiment was repeated (presented as average $\pm \mathrm{SD}, \mathrm{N}=3$ ). Half-time values were determined by linear regression analysis of plots of the logarithm of DHFR-bound drug versus time (0-45 min of displacement). DHFR-bound drug was determined as described in Materials and Methods.

${ }^{*} \mathrm{ND}=$ not determined.

used in these experiments are each pairs of enantiomers, i.e. $\mathrm{D}, \mathrm{L}$-erythro $(2 S, 4 R$ and $2 R, 4 S)$ and $\mathrm{D}, \mathrm{L}-$ threo $(2 S, 4 S$ and $2 R, 4 R)$. Since displacement of radiolabel from $\left[{ }^{3} \mathrm{H}\right] \mathrm{MTX}$-saturated DHFR by $\mathrm{D}, \mathrm{L}-$ MTX $(4$ or $20 \mu \mathrm{M})$ or L-MTX $(2$ or $10 \mu \mathrm{M})$ was comparable (data not shown), we consider it very likely that the D-erythro and D-threo isomers of FMTX have no effect in this system. Our data with racemic MTX is consistent with the data of Cramer et al. [15], suggesting that the D-isomer of MTX is biologically inert, presumably because it is not transported. This indirect evidence suggested that $D-$ erythro-FMTX and D-threo-FMTX would play no part in displacement because they would not enter the cells. Direct proof of this requires pure $L$-enantiomers of FMTX; the synthetically challenging preparation of these enantiomers is currently underway.

Uptake of $\left[{ }^{3} \mathrm{H}\right] e F M T X$ or $\left[{ }^{3} \mathrm{H}\right] t F M T X$ to saturate $D H F R$. The erythro isomer of FMTX is taken up more efficiently than the threo isomer, but both are somewhat less efficient than MTX [8]. Thus, the uptake time required for each $\left[{ }^{3} \mathrm{H}\right]$ isomer at $2 \mu \mathrm{M}$ extracellular concentration to saturate DHFR was determined experimentally, $15 \mathrm{~min}$ for erythro and 20 min for threo (data not shown). In these cases, the presence of unbound drug following uptake was not of such concern since these analogs are poorly glutamylated, if at all [8]. Similar to [ $\left.{ }^{3} \mathrm{H}\right] \mathrm{MTX}$ (Fig. 1), the 30-min efflux period left DHFR saturated with radiolabeled drug, but removed all unbound material (data not shown).

Displacement of $\left[{ }^{3} \mathrm{H}\right]$ eFMTX or $\left[{ }^{3} \mathrm{H}\right] t F M T X$ from intracellular DHFR. Displacement studies of radiolabeled FMTX-isomers from DHFR were performed at various concentrations of unlabeled MTX or FMTX-isomer. The results (Table 2) demonstrated that the $\left[{ }^{3} \mathrm{H}\right]$ erythro isomer was displaced from DHFR slightly more slowly than was $\left[{ }^{3} \mathrm{H}\right] \mathrm{MTX}$ (Table 1); MTX and the erythro isomer were again equivalent as displacing agents except at very low concentrations $(0.5 \mu \mathrm{M})$ where transport of the erythro isomer might be limiting [8]. The $\left[{ }^{3} \mathrm{H}\right]$ threo isomer was displaced from DHFR much more readily than either $\left[{ }^{3}\right]$ MTX or $\left[{ }^{3} \mathrm{H}\right]$ erythro-FMTX. This ready displacement was seen whether the displacement agent was MTX or unlabeled tFMTX. In the absence of MTX or isomer as displacing agent, there was no loss of either radiolabeled isomer from DHFR (data not shown), similar to the case with $\left[{ }^{3} \mathrm{H}\right] \mathrm{MTX}$ (Figs. 1 and 2).

\section{DISCUSSION}

Earlier studies of FMTX, either with a diastereometric mixture [6] or with purified erythro and threo diastereomers [8], compared the interaction with DHFR of these mimics to that of MTX by examining inhibition of isolated enzyme $[6,8]$ and by measuring the degree of association of drug with intracellular DHFR under conditions where drug was limiting [8]. Each type of measurement indicated that the isomers were both equivalent to MTX. Simple measurement of inhibition of DHFR activity (by $\mathrm{IC}_{50}$ value) is not as definitive as determination of $K_{\mathrm{i}}$; however, $K_{i}$ values for stoichiometric inhibitors are difficult to determine with accuracy. The association of drug with intracellular DHFR under conditions of limiting drug [8] measures only one part of this complex interaction. Further insight could be obtained by measurement of the dissociation rate of the inhibitor-DHFR complex.

The studies of Cohen et al. [11], in which displacement by extracellular unlabeled MTX of [ ${ }^{3}$ H]MTX bound to DIIFR was measured, were the first to demonstrate the reversibility of MTX binding to intracellular DHFR and to measure $k_{\text {off }}$ values. Under appropriate conditions, the general approach of this classic paper can be used to examine the interaction of any DHFR inhibitor with intracellular DHFR. For this approach to be valid it is critical that transport of unlabeled displacing agent not be limiting and that sufficient intracellular unlabeled drug be present to block re-binding of radiolabeled drug to DHFR once it dissociates. The finding that the half-times of displacement were the same over a 2- to 5-fold concentration range of displacing agent (Tables 1 and 2) supported the contention that transport was not limiting at the higher concentrations. 
In addition, reciprocal displacement experiments in which each radiolabeled drug was used, in turn, to saturate DHFR allowed differences in transport properties of the FMTX isomers to be rigorously controlled for. The first order decrease in DHFRbound radiolabel without any time lag (Fig. 2) indicated that significant re-binding of radiolabel did not occur. In the present work, the approach of Cohen et al. [11] was also modified by using short uptake times and iced washes to remove extracellular radiolabel in order to eliminate $\left[{ }^{3} \mathrm{H}\right] \mathrm{MTX}$ polyglutamate synthesis, which might confound the results, and by measuring both total and DHFR-bound intracellular radiolabel. Measurement of the DHFR-bound fraction eliminated potential interference by radiolabeled drug which dissociated but did not efflux from the cell (see Fig. 1).

The results of these reciprocal displacement studies (Tables 1 and 2) demonstrated that, under conditions where transport was not limiting, the halftime of displacement (and thus the $k_{\text {off }}$ ) of the erythro isomer of FMTX was essentially the same as that of MTX. The half-time values decreased as the extracellular concentration increased until the proccss appeared saturated; similar saturation was noted in the L1210 system by Cohen et al. [11]. The $k_{\text {off }}$ value determined here at saturation for MTX $\left(4.4 \times 10^{2} /\right.$ min) was also similar to that reported by Cohen et al. [11] in the original work with the L1210 cell line $\left(3.8 \times 10^{-2} / \mathrm{min}\right)$.

In contrast, the interaction of the threo isomer with DHFR was different than that of MTX. The half-time for the displacement of $\left[{ }^{3} \mathrm{H}\right] \mathrm{MTX}$ by the threo isomer (Table 1) was significantly longer than by either MTX or the erythro isomer. This could be the result of either a weaker interaction with DHFR or it could be that the poorer transport of the threo isomer [8] made its concentration limiting, even at a $10 \mu \mathrm{M}$ extracellular concentration. The reciprocal experiment, however, was unambiguous (Table 2). The $\left[{ }^{3} \mathrm{H}\right]$ threo isomer was rapidly displaced from DHFR by either MTX or nonradioactive tFMTX. Any limitation of transport of the nonradioactive displacing tFMTX could, in this case, lead only to an overestimate of the half-time of displacement. A comparison of the displacement half-times of $\left[{ }^{3} \mathrm{H}\right] \mathrm{eFMTX}$ or $\left[{ }^{3} \mathrm{H}\right] \mathrm{tFMTX}$ in the presence of nonradioactive MTX, where transport cannot be an issue, clearly showed that $\left[{ }^{3} \mathrm{H}\right] \mathrm{tFMTX}$ was more readily displaced.

These studies demonstrate that eFMTX dissociated from DHFR at a rate very similar, if not identical, to that of MTX, whereas tFMTX dissociated significantly faster. These results indicate that human leukemia cell DHFR exhibits subtle specificity at the $\gamma-\mathrm{COOH}$ for binding of classical antifols since only the diastereomeric configuration of eFMTX and tFMTX is different. Taken together with earlier data [8] showing that the transport kinetics of eFMTX are also more similar to those of MTX, it can be concluded that, except for glutamylation, eFMTX is a closer mimic of MTX than is tFMTX.

Acknowledgements-This work was supported in part by Grants CA13038, CA24538 (J. J. M.), and CA28097 (J. K. C.) from the National Cancer Institute, Public Health
Service, Department of Health and Human Services, and Institutional Research Grant IN-54Z from the American Cancer Society (J. J. M.). J. J. M. is a Leukemia Society Scholar. The secretarial assistance of Mae Brown is gratefully acknowledged.

\section{REFERENCES}

1. Chabner BA, Allegra CJ, Curt GA, Clendenin NJ, Baram J, Koizumi S, Drake JC and Jolivet J, Polyglutamation of methotrexate. Is methotrexate a prodrug? J Clin Invest 76: 907-912, 1985.

2. Matherly LH, Seither RL and Goldman ID, Metabolism of the diaminoantifolates: biosynthesis and pharmacology of the 7-hydroxyl and polyglutamyl metabolites of methotrexate and related antifolates. Pharmacol Ther 35: 27-56, 1987.

3. Goldman ID, Analysis of the cytotoxic determinants for methotrexate (NSC-740): a role for free intracellular drug. Cancer Chemother Rep (Part 3) 6: 51-61, 1975.

4. Allegra CJ, Chabner BA, Drake JC, Lutz R, Rodbard $\mathrm{D}$ and Jolivet $\mathrm{J}$, Enhanced inhibition of thymidylate synthase by methotrexate polyglutamates. J Biol Chem 260: 9720-9726, 1985.

5. Allegra CJ, Drake JC, Jolivet $\mathbf{J}$ and Chabner BA, Inhibition of phosphoribosylaminoimidazolecarboxamide transformylase by methotrexate and dihydrofolic acid polyglutamates. Proc Natl Acad Sci USA 82: 4881$4885,1985$.

6. Galivan J, Inglese J, McGuire JJ, Nimec Z and Coward $\mathrm{JK}$, Gamma-fluoromethotrexate: synthesis and biological activity of a potent inhibitor of dihydrofolate reductase with greatly diminished ability to form polyr-glutamates. Proc Natl Acad Sci USA 82: 2598-2602, 1985.

7. McGuire JJ, Piper JR, Coward JK and Galivan J, Folate analog nonsubstrates and inhibitors of folylpolyglutamate synthetase as potential cancer chemotherapy drugs. NCI Monogr 5: 139-144, 1987.

8. McGuire JJ, Grabner M, Licato N, Vencenz C, Coward JK, Nimec 7 and Galivan J, Biochemical and growth inhibitory effects of the erythro and threo isomers of $\gamma$ fluoromethotrexate, a methotrexate analog defective in polyglutamylation. Cancer Res, 49: 4517-4525, 1989.

9. McGuire JJ and Coward JK, D, L-threo-4-Fluoroglutamic acid. A chain-terminating inhibitor of folylpolyglutamate synthesis. J Biol Chem 260: 6747-6754, 1985.

10. Bertino JR, Folate antagonists. In: Handbook of Experimental Pharmacology (Eds. Fox BW and Fox M), Vol. 72, pp. 615-631. Springer, Berlin, 1984.

11. Cohen M, Bender RA, Donehower R, Myers CE and Chabner BA, Reversibility of high affinity binding of methotrexate in L1210 murine leukemia cells. Cancer Res 38: 2866-2870, 1978.

12. Foley GF, Lazarus H, Farber S, Uzman BG, Boone BA and McCarthy RE, Continuous culture of lymphoblasts from peripheral blood of a child with acute leukemia. Cancer 18: 522-529, 1965.

13. Fry DW, Yaluwich JC and Goldman ID, Rapid formation of poly- $\gamma$-glutamyl derivatives of methotrexate and their association with dihydrofolate reductase as assessed by high pressure liquid chromatography in the Ehrlich ascites tumor cell in vitro. J Biol Chem 257: 1890-1896, 1982.

14. McGuire JJ, Mini E, Hsieh P and Bertino JR, Role of methotrexate polyglutamates in methotrexate and sequential methotrexate-5-fluorouracil-mediated cell kill. Cancer Res 45: 6395-6400, 1985.

15. Cramer SM, Schornagel JH, Kalghatgi KK, Bertino JR and Horvath C, Occurrence and significance of D-MTX as a contaminant of commercial methotrexate. Cancer Res 44: 1843-1846, 1984. 